\title{
Energy Prices and Short-Run Economic Performance
}

\author{
JOHN A. TATOM
}

$\mathrm{T}$

HE sharp energy price increases that have occurred since late 1978 have profoundly affected the U.S. economy. In particular, the increase in the price of energy resources relative to the price of business output has reduced potential output and productivity, raised the general level of prices, and lowered the optimal capital intensity of U.S. production which, in turn, will temporarily slow real business investment in the early 1980s. Higher energy prices have also had temporary effects on total spending and employment.

The purpose of this article is to explain and assess the magnitude of these energy price effects. Empirical tests are conducted using a reduced-form model for nominal GNP, the price level and the unemployment rate. Real GNP growth is determined implicitly in such a model as the difference between nominal GNP growth and the rate of price increase. This model emphasizes the link between money stock growth and economic activity. The sample period for estimating the relationships ends in the third quarter of 1978 to provide an opportunity to test the stability of the relationships over the past two years, when energy prices increased sharply. Also, major changes in economic policy have occurred since 1978 that may have affected fundamental relationships that explain spending, inflation, output and unemployment. The empirical results, including simulations from the fourth quarter of 1978 to the third quarter of 1980 , strongly support the hypotheses developed below concerning energy price effects. An assessment of the size of the effects of recent energy price increases is obtained from the empirical estimates.

The estimates indirectly imply that, once energy price effects are taken into account, no significant shift in the relationship between the money stock and major measures of economic performance has occurred over the last two years. Neither the shift in focus toward greater emphasis on controlling monetary aggregate growth announced in November 1978 , nor a shift in policy procedures in October 1979 , appear to have exerted independent impacts on the linkages between money and the principal measures of economic performance.

\section{THEORETICAL CONSIDERATIONS}

A simple aggregate supply and demand model will clarify the analysis. ${ }^{1}$ In figure 1 , the economy initially is in equilibrium with price level, $\mathrm{P}_{0}$, and real GNP level, $X_{0}$, at point $A$. The aggregate demand curve, $\mathrm{AD}$, is constructed given levels of such other relevant determinants of demand as current and past monetary and fiscal actions. The aggregate supply curve, SS, is constructed given such other determinants of supply as expected nominal wages, the size of the labor force, the existing capital stock, the relative price of energy, and technology. The price of energy (instead of a quantity of energy) enters the model indicating that the economy in figure 1 is "open;" energy resources can be imported or exported at prices set in a world market. ${ }^{2}$ The aggregate supply curve is constructed with increasing slope to show that at some real output level, it becomes difficult to increase real

\footnotetext{
1 For a more detailed discussion of the theoretical foundation used here, as well as a discussion of alternative macroeconomic approaches itnd empirical evidence from several nations supporting the theory, see Robert H. Rasche and John A. Tatom, "Energy Price Shocks, Aggregate Supply and Monetary Policy: The Theory and International Evidence," forthcoming in the Carnegie-Rochester Conference Series on Public Policy, volume 14, 1981.

It is important to note that the effects of a higher relative price of energy due to exogenous energy market developments do not depend upon the net trade status of the economy.
} 
output despite increases in the general level of prices. At this output level, the economy achieves full employment, utilizing available capital and labor resources. Suppose that such full-employment conditions occur at the initial equilibrium, point $\mathrm{A}$.

When the relative price of energy resources increases, the aggregate supply curve shifts to $S^{\prime} S^{\prime}$. The employment of existing labor and capital with a given nominal wage rate requires a higher general price for output, if sufficient amounts of the higher-cost energy resources are to be used. Of particular interest, however, is the level of output and price level associated with full employment of existing labor and capital. This point is indicated in figure 1 at point $B$, Given the same supply of labor services and existing plant and equipment, the output associated with full employment declines as producers reduce their use of relatively more expensive energy resources and as plant and equipment become economically obsolete. The productivity of existing capital and labor resources is reduced so that potential real output declines to $\mathrm{X}_{1}$. In addition, the same rate of labor employment occurs only if real wages decline sufficiently to match the decline in productivity. This, in turn, happens only if the general level of prices rises sufficiently $\left(\mathrm{P}_{1}\right)$, given the nominal wage rate.

The new equilibrium for the economy occurs at point $B$. For aggregate demand to equal $X_{1}$ at price level $P_{1}$, the aggregate demand curve must be unitelastic with respect to the price level. In the context of the equation of exchange, $M V=Y$ (where $M$ is the money stock, $V$ is its velocity and $Y$ is nominal GNP), this means that velocity is unaffected by a rise in the price level, a standard long-run proposition in monetary theory. ${ }^{4}$

The economy may not adjust instantaneously to point $B$, even if point $B$ is the new equilibrium. For example, price rigidities due to costly information or other transactions costs can keep nominal prices from adjusting quickly. The immediate incentive to cut production and employment indicated by the leftward shift in the aggregate supply curve need not be ac-

\footnotetext{
Whe percentage rise in the price level (percentage decline in the real wage) will equal the decline in productivity, given employment, if the maxginal productivity of labor is proportiond to its average productivity. This proportionclity holds for a Cobb-Douglas production function. "The general case is derived by Rasche and Tatom, "Energy Price-Shocks," Appendix 1 .

The results when some of the assumptions used here are relaxed, especially the short-rm invariance of nominal spending to changes in the price level, are discussed by Rasche and Tatom, "Energy Erice Shocks."
}

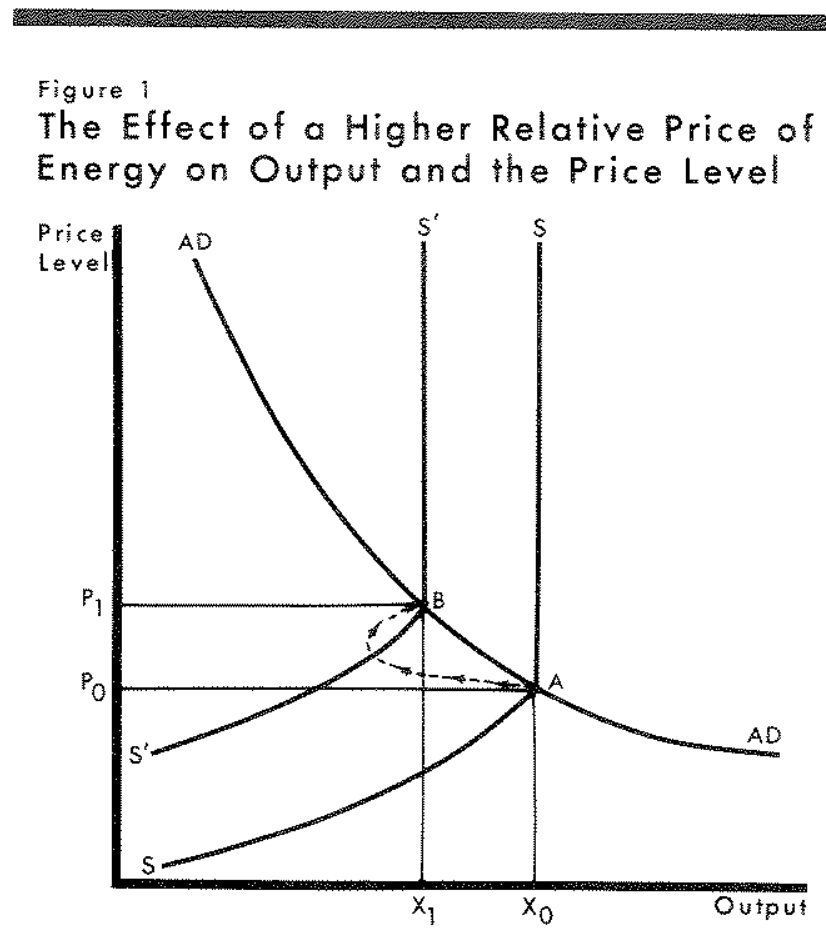

companied immediately by the price level adjustment sufficient to ensure the maintenance of full employment. In this event, disequilibrium GNP will be dominated by the reduction in output before the equilibrium $B$ (and full employment) is achieved. Consequently, output and prices can move along an adjustment path such as that indicated by the arrow in figure 1. The evidence below is consistent with this adjustment process and the hypothesis that GNP is independent of energy price changes, once the adjustment is completed.

\section{EVIDENCE ON POTENTIL OUTPUT AND PRODUCTEVTIT}

The theory and existing evidence on which this article draws deals with isolating the permanent impact of a higher relative price of energy on potential output, productivity, the desired capital-labor ratio and the price level. Before analyzing the dynamics of the short-rum adjustment process, it is useful to review the evidence from a production function approach. Assume that output in the private business sector $\left(Q_{t}\right)$ is a function of hours of employment $\left(h_{t}\right)$, the utilized capital stock $\left(k_{t}\right)$, technological change and the relative price of energy $\left(p_{t}^{*}\right)$. The production function can be written as:

(1) $\ln Q_{5}=\beta_{6}+\beta_{5} \ln h_{t}+\beta_{5} \ln k_{t}+\beta_{5} \ln p_{t}^{6}+\beta_{s} t$ 


\section{Chart l \\ Impact of Energy Price Changes (I/1970-III/1980) on Potential Output Growth in the Private Business Sector 1}

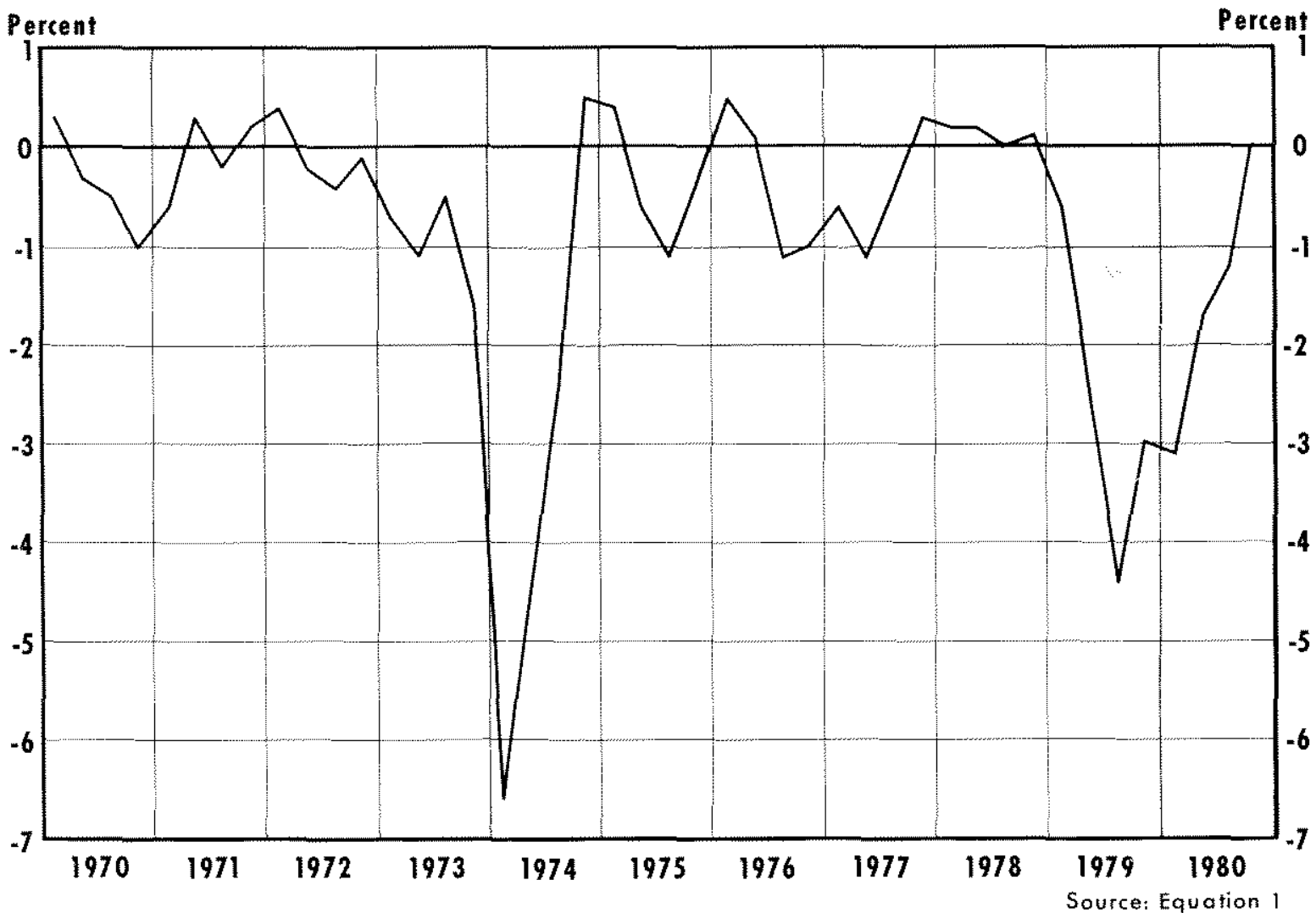

11. Percentage changes are measured in the logarithm of the level of potential output. latest data platfed: Ath quarter

where $t$ is a time trend. ${ }^{5}$ When this equation is estimated for the private business sector over the period I/1955-III/1978, the result is:

$$
\text { (2) } \begin{aligned}
\ln Q_{1}= & 1.464+0.705 \ln h_{t}+0.295 \ln k_{t} \\
& (14.14)(18.10) \quad \\
& -0.093 \ln p^{e}+0.004 t \\
& (-5.06) \quad(13.04)
\end{aligned}
$$

$$
\bar{R}:=0.97 \quad \text { S.E. }=0.007 \quad \text { D.W. }=2.03 \quad \rho=0.81
$$

This estimate is virtually identical to those reported for earlier periods. ${ }^{6}$

"Rasche and Tatom, "Fnerry Price Shocks" and "Energy Resources and Potential GNP," this Review (June 1977), pp. 10-24 derive equation 1 assuming that the production function is Cobb-Douglas and explain the interpretation of the $\beta$ coefficients in tems of output elasticities of inputs. They also describe tests for breaks in the time trend and for the CobbDouglas restrictions.

"For example, see Rasche and Tatom, "Energy Resolrces and Potential GNP." The sample period conforms to that used for the equations estimated below.
Chart 1 shows the direct impact on the annual growth rate of potential output from 1/1970 to III/ 1980 using the energy price coefficient in equation 2. The relative price of energy measure is calculated by deflating the producer price index for fuels and related products and power by the price deflator for private business sector output. Equation 2 indicates that a 40 percent $(\Delta \ln )$ change in the relative price of energy, as occurred from III/1973 to III/1974 or from IV/1978 to II/1980, will permanently reduce potential output and productivity in the private business sector by 3.7 percent. $^{7}$

Although tests conducted to detect statistical biases in estimates such as equation 2 have failed to find any it is possible that quarterly estimates are affected by lagged responses of inputs to ontput that would result in downward biased estimates of the coefficient on the relative price of energy (in absolute size). For example, the estimate of this coefficient using anmual data for the period $1949-75$ is 11.3 percent, implying a 4,5 percent reduction in potential output when energy prices rise 40 percent. 
A rise in the relative price of energy will also reduce the desired capital-labor ratio, temporarily reducing business investment. The theoretical underpinnings and magnitude of the effect of the 1973-74 energy price increases on investment are discussed elsewhere. ${ }^{8}$ Based on that methodology and the coefficient estimates in equation 2, the capital-labor ratio can be expected to decline by 5.3 percent due to energy price increases that occurred from IV/1978 to III/1980. ${ }^{9}$ Productivity growth will tend to be slower than it would have been during the years of adjustment to this decline.

The production function estimates provide evidence that the permanent aggregate supply effects of energy price changes occur quickly. A broader model encompassing aggregate demand considerations is required, however, to assess actual quarter-to-quarter adjustments in spending, output and prices.

\section{THE EFFECT OF ENERGY PRICES ON THE MONEY-GNP LINK}

To examine the temporary adjustments of nominal GNP to changes in the relative price of energy, a variant of the Andersen-Jordan equation from the St. Louis model is used. ${ }^{10}$ This reduced-form equation relates GNP to money stock and high-employ. ment federal expenditure variables. It is usually expressed as:

(3) $\mathrm{GNP}=\beta_{0}+\beta_{2} \sum_{i=0}^{n} w_{t-1}^{0} \dot{M}_{t-1}+\beta_{2} \sum_{j=0}^{m} w_{t-1}^{1} \dot{E}_{t-1}$

8See John A. Tatom, "Energy Prices and Capital Formation: 1972-1977," this Review (May 1979), pp. 2 11.

9Assuming that the price of capital goods relative to business output is unaffected by a rise in energy prices, the elasticity of the desired capital-labor ratio with respect to the relative price of energy is $\left(-\frac{\gamma}{\alpha}\right)$, where $y$ and $\alpha$ are the output elasticities of energy and labor, respectively. Given the estimates in equation $2, \gamma=8.5$ percent and $\alpha=64.5$ percent. Thus, the estimated capital-labor ratio elasticity is 13.2 percent. This figure merely suggests the magnitude, however. When the sam+ ple period is lengthened or annual data is used, the estimate is over 15 percent, not significantly different in a statistical sense, but larger nonetheless. Moreover, it is likely that higher energy prices raise the relative price of goods, further depressing the capitallabor ratio.

16 See Leonall C. Andersen and Jerry L. Jordan, "Monetary and Fiscal Actions: A Test of their Relative Importance in Economic Stabilization," this Review (November 1968), pp. 11-24; Leonall C. Andersen and Keith M. Carlson, "A Monetarist Model for Economic Stabilization," this Review (April 1979), pp. 7-25; and Keith M. Carlson, "Does the St. Louis Equation Now Believe in Fiscal Policy?" this Review (February 1978 ), pp. 13-19. where $\mathrm{G} \dot{\mathrm{N} P}, \dot{\mathrm{M}}$ and $\dot{\mathrm{E}}$ are annual growth rates $\left(400^{*} \Delta \mathrm{ln}\right)$ of $\mathrm{GNP}$, the money stock (M) and highemployment federal expenditures (E). The coeffcients on current and lagged $\dot{\mathrm{M}}$ and $\dot{\mathrm{E}}$ variables are estimated using Almon polynomials. The polynomial degree, lag length and constraints for $\dot{M}$ and $\dot{E}$ coefficients are those used in the model - fourth degree polynomials with five lags and head and tail constraints.

Since major strikes temporarily reduce and subsequently increase GNP growth, a variable is included to capture these temporary influences. ${ }^{11}$ This variable, $S_{t}$, is the change in the quarterly average of "days lost due to strikes," deflated by the civilian labor force.

Monetary aggregates have been revised to reflect the existence of transactions balances not held either as currency or demand deposits at commercial banks. The new measure of the money stock that can be used directly for transactions purposes is $\mathrm{MLB}$, but data on this measure exist only since 1959 . The difference in this measure and the old measure, $M 1$, is very small in 1959. More important, the growth rates of both M1 and M1B are roughly the same until the early 1970s. Consequently, the growth of the money stock $\mathrm{M} 1$ is used in the estimation of equation 3 for quarters in the sample period prior to 1959 . This practice is further supported by the fact that the properties and coefficients of the estimated equation are virtually identical to old estimates using M1 for sample periods prior to the rapid growth of transactions balances in savings accounts with the automatic transfer service.

The GNP equation, estimated for the period I/ 1955 to $\mathrm{III} / 1978$ is:

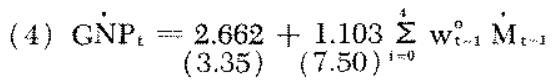

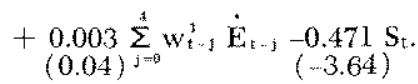

$$
\begin{aligned}
& \overline{\mathrm{P}}^{2}=0.46 \quad \text { S.E. }=3.18 \quad \text { D.W. }=1.88
\end{aligned}
$$

The equation has the usual properties that the sum of the coefficients on money stock growth is not significantly different from one, and that the sum of expenditure effects is not significantly different from zero. The strike variable is significant and has the right sign; the mean value of the strike variable is

\footnotetext{
${ }^{11 S e e}$ Leonall C. Andersen, "A Monetary Model of Nominal Income Determination," this Review (June 1975), pp. 9-19, for an example of using strike dummies in such a GNP equation.
} 
0.017 , so that the mean strike effect is only -0.008 percent.

To examine the impact of the relative price of energy on GNP, current and lagged values of the annual growth rate of the relative price of energy are added to equation 4 . A search was conducted for the optimal lag length using $\mathrm{F}$-tests for each additional lagged value of the growth of the relative price of energy and for additional groups of lagged values (up to five at a time). The criterion for including lags is the 5 percent significance level. $U_{p}$ to 16 lagged values were examined. The same examination was conducted using polynomial distributed lags up to the fourth degree, with and without end-point constraints. The results are virtually identical to those reported below and the polynomial restriction is unimportant. The polynomial distributed lag results are discussed in the appendix.

The optimal lag length includes the current and six past values of the growth in the relative price of energy. The equation estimate with the unrestricted distributed lag for energy prices is:

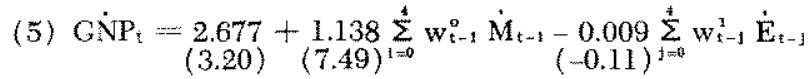

$$
\begin{aligned}
& -0.443 \mathrm{~S}_{1}-0.050 \dot{\mathrm{p}}^{\mathrm{e}} \\
& (-3.54) \quad(-1.32)
\end{aligned}
$$

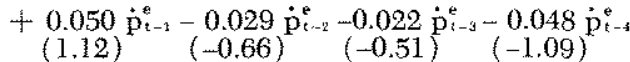

$$
\begin{aligned}
& +0.012 \dot{\mathrm{p}}_{\mathrm{t}-\mathrm{z}}^{\mathrm{z}}+0.106 \dot{\mathrm{p}}_{\mathrm{t}-\mathrm{q} .}^{\mathrm{e}} \\
& (0.28) \quad(2.83) \\
& \overline{\mathrm{R}}^{2}=0.52 \quad \text { S.E. }=2.97 \quad \text { D.W. }=1.91
\end{aligned}
$$

An $\mathrm{F}$-test ( 5 percent significance level) of adding the energy price terms to equation 4 rejects the hypothesis that each of the energy price coefficients is zero $\left(F_{7,88}=2.63\right)$. The coefficients on the variables in equation 4 are not changed significantly in estimating equation 5 .

The coefficients on the relative price of energy can be used to determine the effect on nominal spending of an increase in the growth rate of energy prices or of a once-and-for-all rise in energy prices. The sum of the coefficients on the rate of increase in energy prices indicates the long-run effect on the growth of nominal GNP of a 1 percentage-point increase in the annual rate of energy price increases. This sum also indicates the effect on the level of GNP of a once-and-for-all rise in the relative price of energy. Consider an $x$ percent rise in the relative price of energy in the current quarter. Such a rise affects GNP in the current quarter and results in a difference in the logarithm of
GNP. An effect on GNP continues, according to equation 5, for six more quarters, even though the change in the relative price of energy is zero in subsequent quarters. The pattern of coefficients on the energy price terms indicates that a current-quarter rise in the relative price of energy tends to reduce nominal GNP for six quarters, then increases it.

In order to test the hypothesis that a change in the relative price of energy has no lasting effect on nominal GNP, equation 5 is estimated with the sum of the energy price coefficients constrained to zero. The F-statistic for the addition of the freely estimated coefficient in equation 5 is $F_{1,80}=0.13$, which is not significant at the 1 percent level. The constraint that the sum of the relative price of energy effects on GNP is zero cannot be rejected. The constrained equation is:

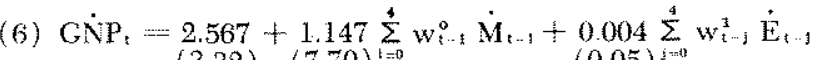

$$
\begin{aligned}
& (3.32)(7.70)^{i=0} \quad(0.05)^{j=0} \\
& -0.444 \mathrm{~S}_{\mathrm{t}}-0.054 \hat{\mathrm{p}}_{\mathrm{t}}^{\mathrm{e}}+0.049 \hat{\mathrm{p}}_{\mathrm{t}-1}^{\mathrm{e}} \\
& (-3.57) \quad(-1.49) \quad(1.10) \\
& -0.031 \dot{\mathrm{p}}_{\mathrm{t}-2}^{\mathrm{e}}-0.025 \dot{\mathrm{p}}_{\mathrm{t}-3}^{\mathrm{e}}-0.050 \dot{\mathrm{p}}_{\mathrm{t}-\mathrm{t}}^{\mathrm{e}} \\
& (-0.73) \quad(-0.58) \cdot(-1.16) \\
& +0.010 \dot{\mathrm{p}}_{\mathrm{c}-\bar{s}}^{\mathrm{c}}+0.101 \dot{\mathrm{p}}_{\mathrm{p}-4 \mathrm{~s}}^{\mathrm{w}} \\
& (0.22)^{(2.87)} \\
& \overline{\mathrm{R}}^{2}=0.53 \quad \text { S.E. }=2.95 \quad \text { D.W. }=1.91
\end{aligned}
$$

The F-statistic for the addition of the six independently estimated variables in equation 6 to equation 4 is $F_{6,81}=3.08$, which exceeds the critical $F_{\text {-statistic }}$ at the 1 percent significance level, so that the hypothesis that each of the relative price of energy coefficients is zero is again rejected. None of the coefficients in equation 6 is significantly different from those in equation 5. Equation 6 not only supports the hypothesis that there is no permanent effect of the relative price of energy on GNP, it also provides evidence on the adjustment process with price rigidities. Initially, nominal GNP is reduced by an increase in the relative price of energy, as nominal GNP is dominated by the real output effect discussed above. Only later do price level effects reverse this nominal GNP development, After six quarters, the transitory movements in GNP have washed out. The theoretical proposition that the shift in aggregate supply due to energy price changes leaves nominal demand unchanged is supported by the estimated equation.

Energy price changes have been substantial since the end of the sample period for equations 4-6. Moreover, the growth of the money stock has been erratic since the end of the third quarter of 1978 , 
Table 1

\section{Simulation of Equation 6}

\begin{tabular}{|c|c|c|c|}
\hline $\begin{array}{l}\text { One-quarter } \\
\text { period ending }\end{array}$ & Actual GNP & Simulated & Error \\
\hline W/1978 & $14.6 \%$ & $14.6 \%$ & $00 \%$ \\
\hline $1 / 1979$ & 119 & 109 & 10 \\
\hline $1 / 1979$ & 58 & 8.3 & 25 \\
\hline $11 / 1979$ & 11.5 & 115 & 0.1 \\
\hline N/1979 & 85 & 12.3 & 39 \\
\hline 11980 & 119 & 90 & 20 \\
\hline $1 / 1980$ & 11 & 3.4 & 4.5 \\
\hline 1111980 & 112 & 5.6 & 5.5 \\
\hline & & Mean error & 0.17 \\
\hline
\end{tabular}

1 Figures hray not add exaclly due to rounding

especially in 1980 . Thus, the ability of equation 6 to simulate the post-sample experience is a strong test. Using actual data for money stock, federal expenditures, and relative price of energy growth rates for the period IV/1978-III/1980 results in the predicted growth rates of nominal GNP shown in the second column of table 1. Column 1 shows the actual GNP growth rates. The third column shows the simulation errors (simulated growth minus actual growth).

Equation 6 tracks extremely well in the eightquarter post-sample period. The errors in the last two quarters, however, suggest that the credit control program in the second quarter and its removal in the third quarter had an impact. Over the eight quarters, the mean error is 0.05 percent and the root-meansquared error (RMSE) is 3.2 percent, only slightly larger than the standard error of the equation. For the first six quarters of the simulation, the mean error is 0.33 percent and the RMSE is 2.23 percent, less than the standard error in equation 6 .

The importance of the temporary energy price effects emerges from the same simulation experiment using equation 4 , which ignores energy prices. The simulated GNP growth rates and residuals are shown in table 2. Ignoring temporary energy price effects leads to over-estimates of GNP growth. The mean error is 1.2 percent for the eight quarters and 1.0 percent for the first six quarters, much larger than in table 1. The size of each of the residuals in table 2 is generally larger than in table 1. The RMSE is larger

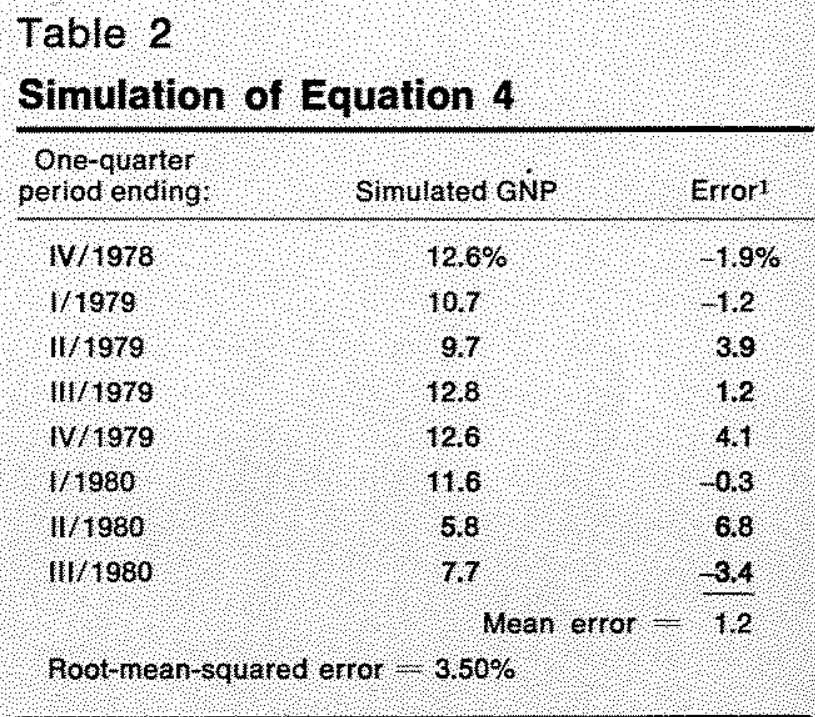

THgures nat not add exactly dere to rounding.

than the standard error in equation 4 and larger than in table 1.

Despite the quality of the simulation results for equation 6 , it must be noted that the economy has seldom been forced to adjust to large changes in the relative price of energy. Thus, the estimates in equations 5 and 6 may be heavily influenced by the parm ticular events surrounding 1973-75 developments. To examine this possibility, the sample period for equations $4-6$ is extended to III/1980. A search for the optimal lag structure was conducted again, using the criterion and selection procedure described above. The optimal lag structure is the same, the current and six lagged values of the growth of the relative price of energy. The sign pattern, magnitude and significance of all the coefficients, including the relative price of energy terms, are essentially unchanged when the sample period is extended. The equations have about the same adjusted $R^{2}$ and standard error when the sample period is extended. Estimated over the longer sample period, equation 6 is:

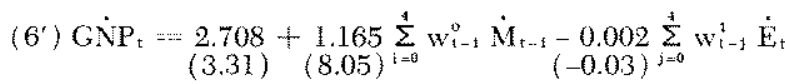

$$
\begin{aligned}
& -0.453 S_{1}-0.062 \dot{p} \dot{p}^{e} \\
& (-3.71)(-1.93)
\end{aligned}
$$

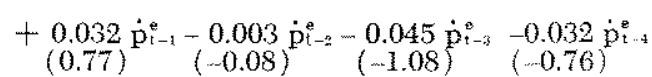

$$
\begin{aligned}
& +0.010 \dot{\mathrm{p}}_{-\overline{\mathrm{s}}}^{\mathrm{e}}+.099 \dot{\mathrm{p}}_{-\mathrm{E} \text {. }}^{\mathrm{e}} \\
& (0.24)^{p(2.93)} \\
& \overline{\mathrm{R}}^{-2}=0.54 \quad \text { S.E. }=2.96 \quad \text { D.W. }=1.99
\end{aligned}
$$




\section{Chart 2 \\ Contribution of Energy Price Changes (I/1970-III/1980) to GNP Growth}

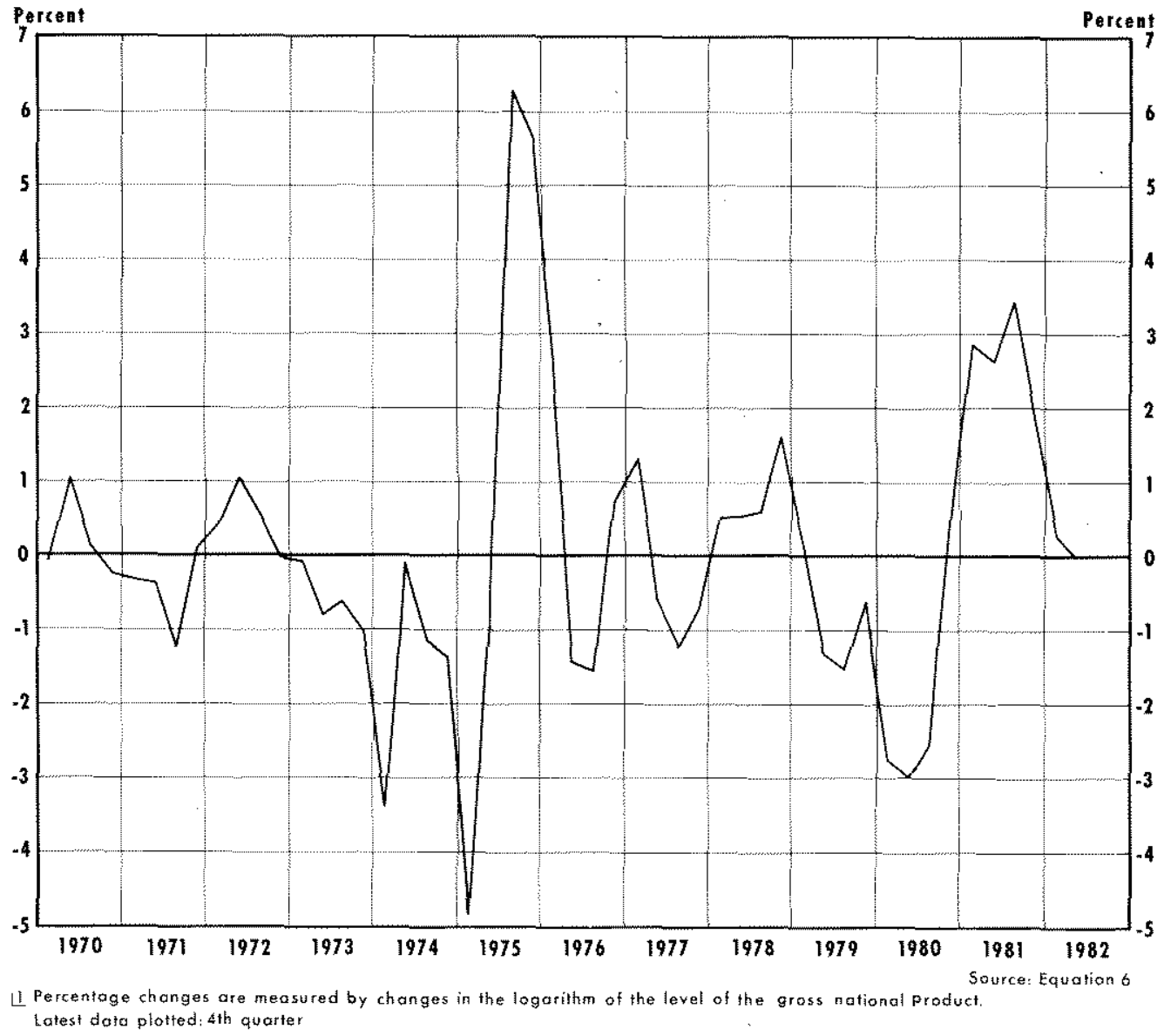

When equation 4 is estimated over the same sample period (I/1955-III/1980), it too does not change significantly (the standard error is 3.18 percent). The F-statistic for the addition of the relative price of energy terms, $F_{6,89}=3.47$, is significant at the 1 percent level. The lag structure, size and significance of the energy price effects in equation 6 do not appear to be artifacts of the $1973-75$ experience.

To provide a longer perspective on the relative price of energy's impact on GNP, as well as a more balanced perspective on recent developments, chart 2 provides estimates of the impact of actual energy price developments on GNP growth for each quarter from $1 / 1970$ to II/1982 using the coefficients in equation 6. These estimates span three diverse periods from a statistical view: the period 1/1970-III/1978 is within the sample period for equation 6 ; the period IV/1978-III/1980 is that of the post-sample simula- tion of equation 6 ; and the estimates for IV/1980-II/ 1982 are based on the assumption that the relative price of energy does not change in IV/1980-II/1982. The chart shows that current and past energy price changes exerted large negative impacts on GNP growth from I/1974 to I/1975 and from II/1979 to III/1980. In the first instance, these changes were offset by the subsequent positive effects of past energy price increases in III/1975-I/1976. It remains to be seen whether the large offsetting reactions of GNP growth to past energy price changes shown from IV $/ 1980-I V / 1981$ will materialize. ${ }^{12}$

\footnotetext{
12An important caveat is necessary. The assumption that the relative price of energy remans unchanged after III/1980 is included to illustrate the presence, size and pattern of lagged effects of past energy prices on future GNP growth.

It is well known that the relative price of energy will rise over the year III/1980-III/1981 dise to U.S. energy policy. The quarterly timing of this increase, however, is not known with a high degree of certainty.
} 


\section{ENERGY PRICES, THE MONEY-PRICE LINK AND REAL GNP DEVELOPMENTS}

The effect of a change in the relative price of energy on the general level of prices can be examined in the context of a simple reduced-form equation that focuses on the link between money and prices. In particular, the rate of increase in the GNP implicit price deflator is primatily determined by growth in the stock of money. Prior evidence indicates that the growth of the money stock over the past 20 quarters (five years) is a significant determinant of the rate of increase in prices. ${ }^{13}$ The period of wage-price controls, which falls within the sample period, had a significant impact on prices. Controls temporarily reduced price increases, then temporarily raised the rate of increase. Dummy variables are included in the price equations estimated here to account for these effects. ${ }^{14}$

To investigate the effect of changes in the relative price of energy on the price level, current and lagged values of the rate of change in the relative price of energy are added to the reduced-form relationship between money growth and rate of price increase $P_{\text {t }}$. The basic price equation, without energy price variables, for the period 1/1955-111/1978 is:

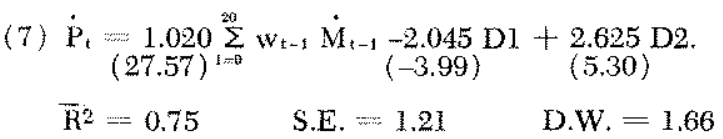

${ }^{13}$ See Denis S. Karnosky, "The Link Between Money and Prices: 1970m76," this Review (June 1976), pp. 17+23. Karnosky shows the permanent inmact of a higher relative price of energy on the price level, and the absence of a permanent wage and price control effect. The approach below differs slightly. The relative price of energy is used in the price equation instead of a dummy varable for the energy price eftect, and the timing of wage and price control effects is different. Also, Keith M. Carlson, "The Lag from Money to Prices," this Review (October 1980), pp. 3-10, argues that since 1970 the length of the lag for past money growth has shortened to 12 quarters. This result does not hold for equation 8 below. The optimal lag length for the period $[/ 1970-11 / / 1978$ for this equation is 22 quarters, virtually the same as used here.

${ }^{14}$ For the control period, JI/ $1971-1 / 1973$, the dummy variable Dl has a value of unity, and zero in other periods. The dzmmy variable D2 has a value of unity in $1 / 1973-1 / 1975$ and zero otherwise, to capture the effects of the ending of price controls. The choice of the periods for control and decontrol effects is largely motivated by the findings reported by Alan S. Blinder and William J. Newton, "The 1971-1974 Controls Program and the Price Level: An Econometric Post-Mortem, National Bureau of Econonic Research, Inc. Working Paper No. 279 (September 1978). Their results, for the monthly consumer price index, support the view that the retarding effects of controls on inftation ended in early 1973 and that these effects were offset by "eatch wup" inflation that began at that time and continued until the first quarter of 1975 . Earlier experiments with varying the timing of this specification resulted in higher standart errors for the price equations 7 and 8 .
Table 3

Simulation of Equation 8

\begin{tabular}{|c|c|c|c|}
\hline $\begin{array}{l}\text { Ore quarter } \\
\text { period ending }\end{array}$ & ActualP & simulatedP & Error \\
\hline $\mathrm{V} / 1978$ & $9.3 \%$ & $61 \%$ & $3.2 \%$ \\
\hline $1 / 1979$ & 81 & 62 & 19 \\
\hline 111979 & 75 & 65 & 1,0 \\
\hline $11 / 1979$ & 75 & 25 & 00 \\
\hline N/1979 & 78 & 8.6 & 0,7 \\
\hline 11960 & 89 & 92 & 03 \\
\hline $11 / 1980$ & 9.4 & 84 & 09 \\
\hline \multirow[t]{2}{*}{$11 / 1980$} & 88 & 9.6 & 0.8 \\
\hline & & Meanerror & 07 \\
\hline Root-mean & error & $18 \%$ & \\
\hline
\end{tabular}

TF gures nay not add exacty dine to romding.

Since a constant is not significant in any of the price equations estimated, it is omitted. The sum of money growth coefficients is not significantly different from unity; the price control dummy variables are signifcant and have the correct sign. A test of the hypothesis that price controls had no permanent impact on the price level could not be rejected at the 5 percent significance level, although that constraint is not imposed here. Twenty lagged money growth rates were included because, for a variety of sample periods examined previously, this lag length is optimal (minimum standard error). A third-degree polynomial distributed lag with a tail constraint is used to estimate the current and lagged money growth coefficients.

Up to 16 lagged values of the rate of change in the relative price of energy were examined using an unrestricted distributed lag. An F-test ( 5 percent significance level) was used for the significance of additional lagged values and sets of lagged values. In no case is the current energy price variable significant (generally its t-statistic is less than one-half in absolute value and usually has a negative sign), so it is dropped. The optimal lag structure includes four lagged values of the rate of increase in the relative price of energy. This equation is:

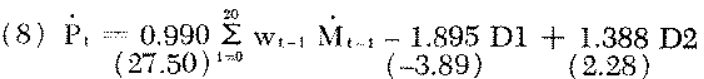

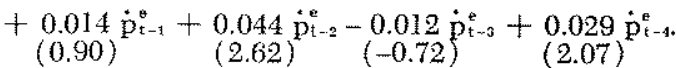

$$
\begin{aligned}
& \overline{\mathrm{R}}^{2}=0.78 \quad \text { S.E. } \cdots 1.15 \quad \text { D.W. }=1.74
\end{aligned}
$$




\section{Chart 3 \\ Contribution of Energy Price Changes (1/1970-III/1980) to the Rate of Increase of Prices $₫$}

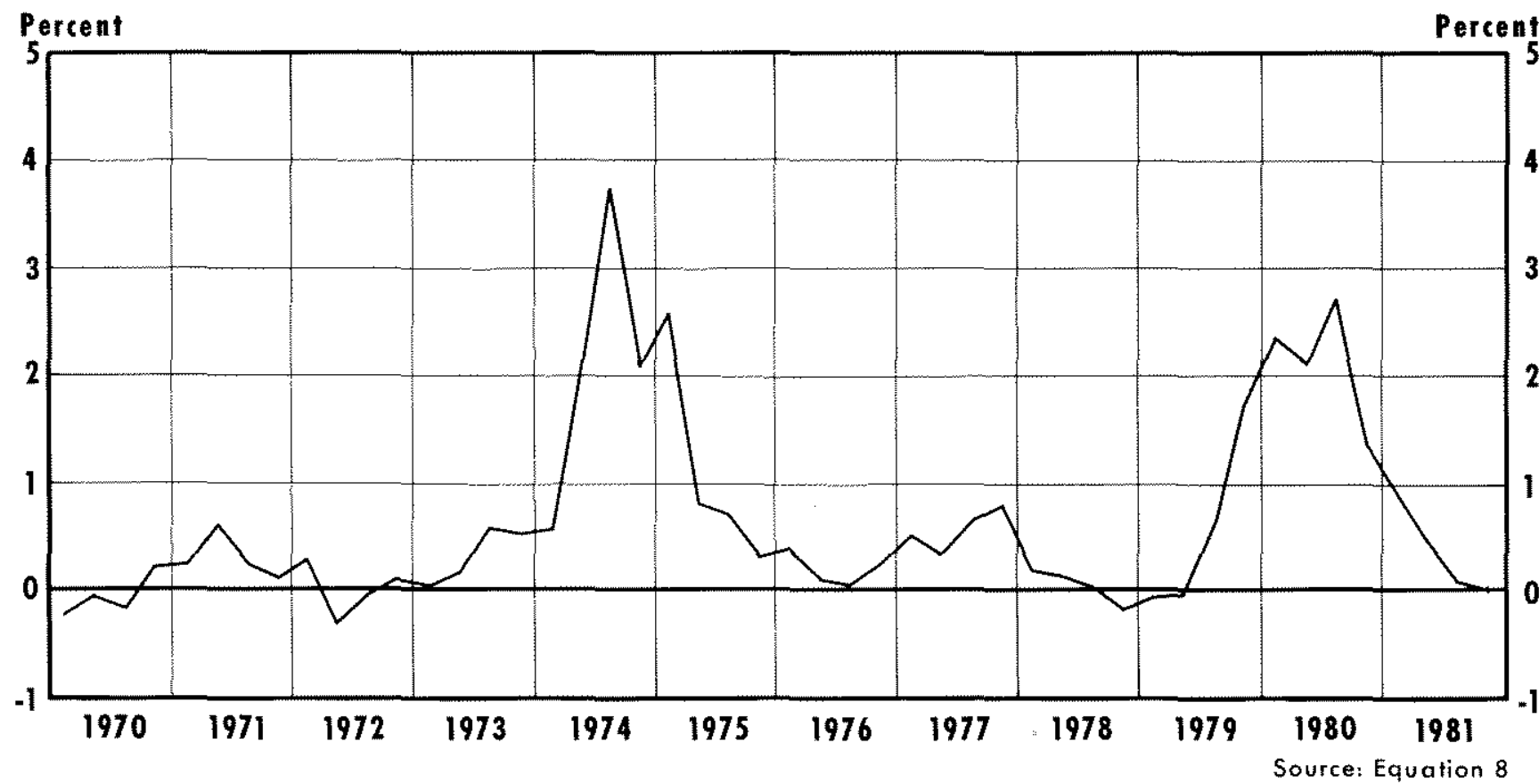

1 Percentage changes are measured by changes in the logarithm of the level of the gross national product deflator. Latest data plotted: 4 th quarter

The F-statistic for the addition of the four lagged energy price terms to equation $7, F_{4,86}=3.63$, is significant at the 5 percent level. ${ }^{15}$

The sum of the energy price effects on the level of the GNP deflator in equation 8 is 0.075 (S.E. = $.0235)$. For the sample period $1 / 1955-I I I / 1978$, the elasticity of potential private business sector output with respect to the relative price of energy is -0.093 , according to equation 2. The price level elasticity of the relative price of energy in equation 8 is not significantly different from this estimate. Thus, the hypothesis that the price level effect is the same as the

\footnotetext{
15 Since the GNP and the price estimates are reduced-form equations, the exogerous variables in each are potentially the same. When the wage and price control dummies and the additional lagged money terms included in equation 8 are added to the GNP equation 6 , none of the coefficients is signiffcant individually or as a group at the 5 percent significance level. 'Thus, these variables are not included in equation 6. Also, wher the strike variable and expenditure variables included in equation 6 are added to the price equation 8 , they too are insignificant (all $\mathrm{t}$-statisties are less than $0.4 \mathrm{in}$ absolute value), so they are omitted. It can be concluded that equations 6 and 8 are drawn from the same model with a common set of exogenous variables.
}

decline in potential output is not rejected. This rein forces the earlier result that a rise in the relative price of energy has no permanent effect on nominal GNP.

The results of a post-sample simulation of equation 8 are shown in table 3 . The rate of price increase is underestimated during late 1978 and early 1979. Begimning in II/1979, however, the errors are quite small. The average error for the last six quarters in the post-sample period is -0.01 percent. For the eight-quarter period, the average error is -0.7 perm cent. The RMSE of 1.5 percent is not significantly larger than the standard error during the sample period. ${ }^{16}$ These results contrast shapply with a simulation of equation 7 , which omits energy price

16When equations 7 and 8 are reestimated through the third quarter of 1980 , there are no important changes in the optimum lag length, the coefficient estimates or the fit of the equations. The standard error of equation 8 rises to 1.169 and the adjusted $\mathrm{R}^{2}$ rises to 0.80 . The pattern of energy price coefficients remains the same and the sum effect for a rise in the relative price of energy is 0.066 , essentially the same as above. The sum of the money growth coefficients (1.015) remains essentially unity. The F-statistic for the addition of the energy price coefficients is $\mathrm{F}_{4,3}=4.46$, which is significant at the 1 percent level. 

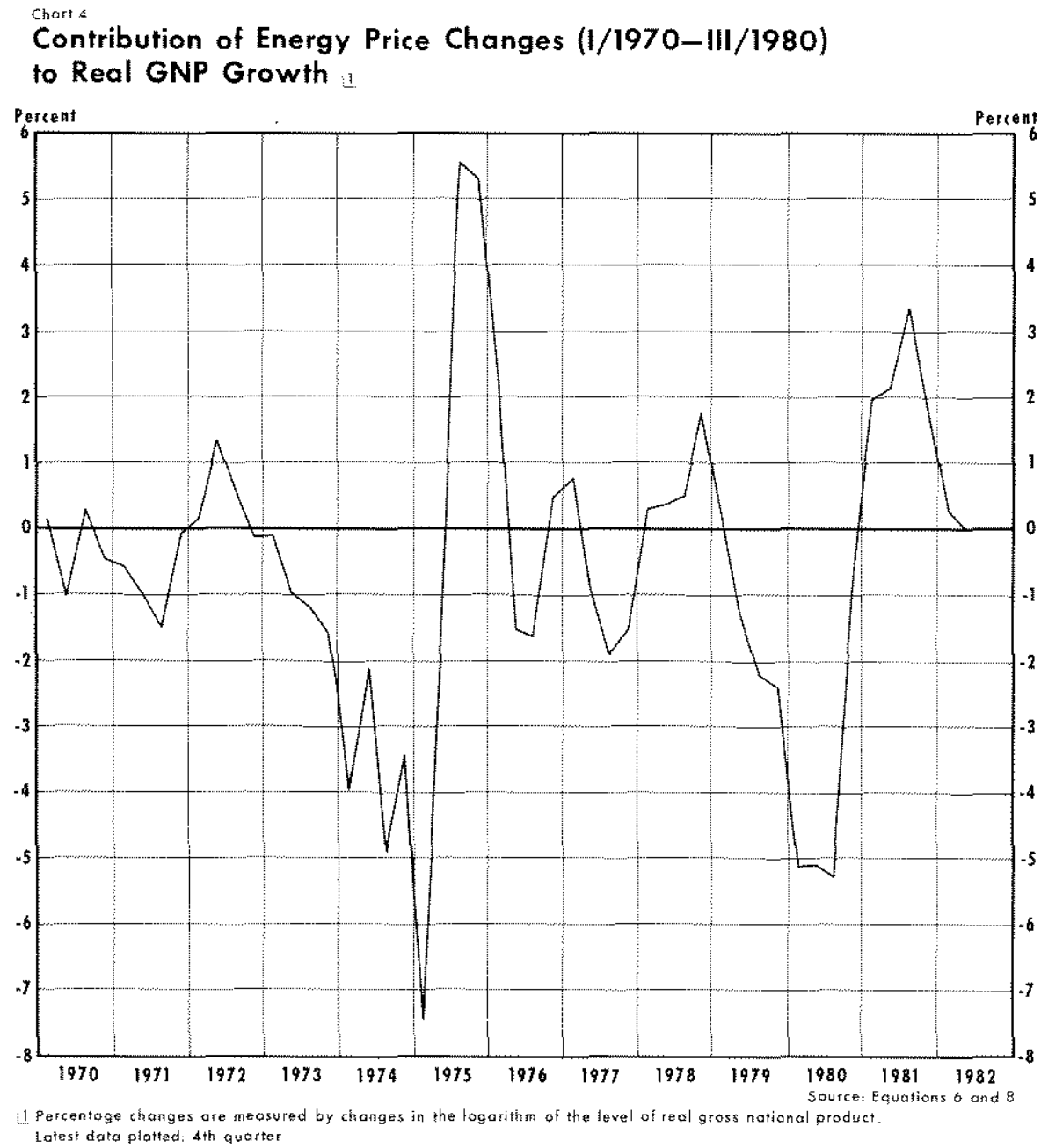

changes. For the same eight-quarter period, the simulation of equation 7 underestimates inflation in every quarter by an average of 1.8 percent (RMSE = 1.93). The differences are particularly large beginning in the third quarter of 1979 when the simulation error for equation 7 is -0.8 percent; thereafter, the error is -0.9 percent, -1.9 percent, -2.6 percent and -1.7 percent, respectively.

The impact of energy price changes on prices and observed real output can be found from equations 8 and 6. Chart 3 shows the contribution of changes in the relative price of energy to the rate of price increase from I/1970-IV/1981 under the assumptions used above for the effects on GNP growth. Changes in the relative price of energy have had negligible impacts on the GNP deflator except following the two periods of sharp increases. In the first instance, the rate of increase in the GNP deflator was raised on average by over 2 percentage points during the four quarters from $\mathrm{I} / 1974$ to $\mathrm{I} / 1975$. The same result occurred from III/1979 to III/1980. On an annual basis, the price level impact exceeded 0.6 percentage points in only three years: 1974 and 1980, when the impact was an additional 2.1 percentage points, and 1975 , when it was 1.1 percentage points.

The GNP and price level effects are combined in chart 4 to obtain real GNP effects. In general, chart 4 shows the negative permanent impact of the sharp increase in relative energy costs in 1973-74 and 1979 . 80. This effect, however, is mixed with the transitory impact associated with the dynamic adjustments of output and prices due to the supply shock.

In table 4 the cumulative impact of a 40 percent increase in the relative price of energy in the current quarter is indicated for GNP, prices, and the difference, real output. ${ }^{17}$ Note that after six quarters, there is no effect on GNP, the price level is 3.0 percent higher and real output is 3.0 percent lower. These develop- 
ments illustrate the permanent effects of the energy price increase. During the transition, however, GNP is relatively lower and prices are affected somewhat less than their permanent changes. Real output does not fall as much as its permanent decline until two quarters after the energy price rise. Subsequently, real output overshoots its ultimate decline, then returns to the level of the permanent decline. If the permanent effect on real output is taken to be an estimate of the immediate potential output effect, the gap between potential output and actual real GNP initially narrows so that the unemployment rate for the labor force declines. Subsequently, actual output is reduced relatively more than its permanent decline so that the unemployment rate will temporarily rise. After six quarters, the decline in real GNP is the permanent change. According to the theory, the permanent decline arises because of a fall in potential output and productivity. Consequently, the unemployment rate would not be expected to change beyond the period of transition.

\section{ENERGY PRICES, THE MONETARY GOWTIIUNEMPLONMENT RATE LINE}

Transitional memployment can be examined using a reduced-form equation similar to those above. The general theoretical considerations that are useful here are (1) that the economy tends to full-employment equilibrium unless disturbed by shocks such as policyinduced fluctuations in aggregate demand or supply, and (2) that demand-stimulus, especially through changing the rate of money stock growth, can temporarily reduce the unemployment rate. These considerations have been explored to a limited extent in a reduced-form framework, ${ }^{18}$ The hypothesis that the unemployment rate equals the full-employment unemployment rate plus a component that rellects the past history of money growth that leads to temporary departures of the economy from full-employment could not be rejected.

For the hypothesis examined here, changes in the excess of the unemployment rate (U) over a full-

\footnotetext{
${ }^{1} \mathrm{~A}$ once-and for-all tise in the relative price of energy of 40 percent is equivalent to a 160 percent increase during the current quater, wher measured at an annual rate. The GNP effect is found by summing the energy price coefficients times $160 \mathrm{in}$ equation 6 , and dividing by four to obtain quarterly differences. The price effects are found by summing the coefficients in equation 8 , and again multiplying by $40(160 / 4)$.

18See John A. Tatom, "Does The Stage of the Business Cycle Affect the Inflation Rate?" this Review (September 1978), pp. 7.15 .
}

\section{Table 4}

\section{The Effects of a $\mathbf{4 0}$ Percent Increase in the Relative Price of Energy}

\begin{tabular}{cccc}
\hline Quarter & GNP & Prices & Real output \\
\hline 0 & $-2.14 \%$ & 0 & 0 \\
1 & -0.20 & 0.54 & $-2.14 \%$ \\
2 & -1.45 & 2.31 & -0.74 \\
3 & -2.44 & 1.82 & -2.32 \\
4 & -4.45 & 3.00 & 4.26 \\
5 & -4.06 & 3.00 & -7.45 \\
6 & 0 & 3.00 & -7.06 \\
7 & 0 & 3.00 & -3.00 \\
\hline
\end{tabular}

employment unemployment rate $\left(U_{F}\right)$ are taken as the dependent variable, $\Delta \mathrm{UN}$, where $\mathrm{UN}=\left(\mathrm{U} \sim \mathrm{U}_{\mathrm{F}}\right)$. The full-employment unemployment rate is that developed by Clark (1977). ${ }^{19}$ Changes in excess unemployment are potentially a function of the exogenous variables considered above.

An examination of such a relationship yields the following results. First, the federal expenditure growth variables and strike variable that enter the GNP equation 6 are not significant in any of the equations estimated. While the coefficient estimates for current and past federal expenditure growth variables have the expected sign pattern - initially negative, then positive - none of the t-statistics for the individual coefficients or sum coefficients is larger than 0,4 in absolute value. In addition, the F-statistic for the set of federal expenditure variables is less than 0.1 , so they are omitted below. Also, the strike variable in equation 6 and the wage and price control dummy variables in the price equation 8 do not have t-values in excess of one in any of the unemployment equation estimates, so they too are omitted. ${ }^{20}$ Finally, a constant term was not significant in any of the estimated equations, so it is omitted.

\footnotetext{
19See Peter K. Clark "Potential GNP in the United States, 1948-80" U.S. Productive Capacity: Estimating the Utilization Gap, (St. Loujs: Center for the Study of American Business, Washington University, 1977), pp. 21-66.

$20 T h$ is is in sharp contrast to the view that controls distorted the observed relation of unemployment to output growth expressed by Michael R. Darby, "Price and Wage Controls: The First Two Years," "Price and Wage Controls: Further Evidence" in Karl Brinner and Allan H. Meltzer, eds. The Economics of Price and Wage Controls, Camegie-Rochester Conference on Public Policy Series, supplement to the Journal of Monetary Economics, Volume 2 (1976).
} 
A search for the optimum lag structure for energy price changes and monetary growth was conducted. The criterion for the optimum lag for energy prices was an $F$-test at the 5 percent significance level for the addition of past energy price changes. This test was conducted for several specifications of the lag length (6 to 30 quarters) for current and past money growth effects. In every case, the optimum structure includes the past six quarters of relative energy price changes. Since the current-quarter effect never has a $t$-value as large as 0.5 in absolute value, it is omitted. The criterion for selecting the optimum lag structure for a third degree polynomial lag of current and past money growth is to minimize the standard error of the equation estimated with the six past energy price terms, with and without the other variables discussed above. The optimum lag structure in every case includes the current and nine past money growth rates.

The choice of the 10-quarter period for money growth effects is highly suspect, but fortunately it does not affect the energy price estimates. In particular, changes in the unemployment rate are expected to be a function of changes in the "GNP gap" in an Okun's Law framework. Changes in the GNP gap, in turn, are a function of the growth rate of potential output and the growth rate of actual output. According to the GNP and price results above, the growth rate of actual output is affected by money stock growth for about five years, so changes in the excess unemployment rate would be expected to have the same lag structure. In searching the lag space, equations with 22 lagged money growth rates had a local minimum standard error for lags from 10 to 30 quarters, and this standard error is 0.8 percent higher (0.264 for equation 9 ) than with nine lagged terms. None of the properties of equation 9 are altered when 22 lagged values of money growth are included. In particular, the optimum lag, sign pattern, magnitude and t-statistics for the individual energy price terms are identical, as is the F-test for the addition of these terms. The difference is that after the winth lag, money growth coefficients are initially small and positive, then small and negative with a sum that is not significantly different from zero. Because of the criterion adopted for selection of the optimum lag structure, and the independence of the energy price effects to the lag structure choice, the shorter lag for money growth is used here.

The unemployment rate equation 9 is presented in table 5 . Note that an increase in the rate of money growth has a transitory effect, leading to reductions in the excess unemployment rate for five quarters. Sub-

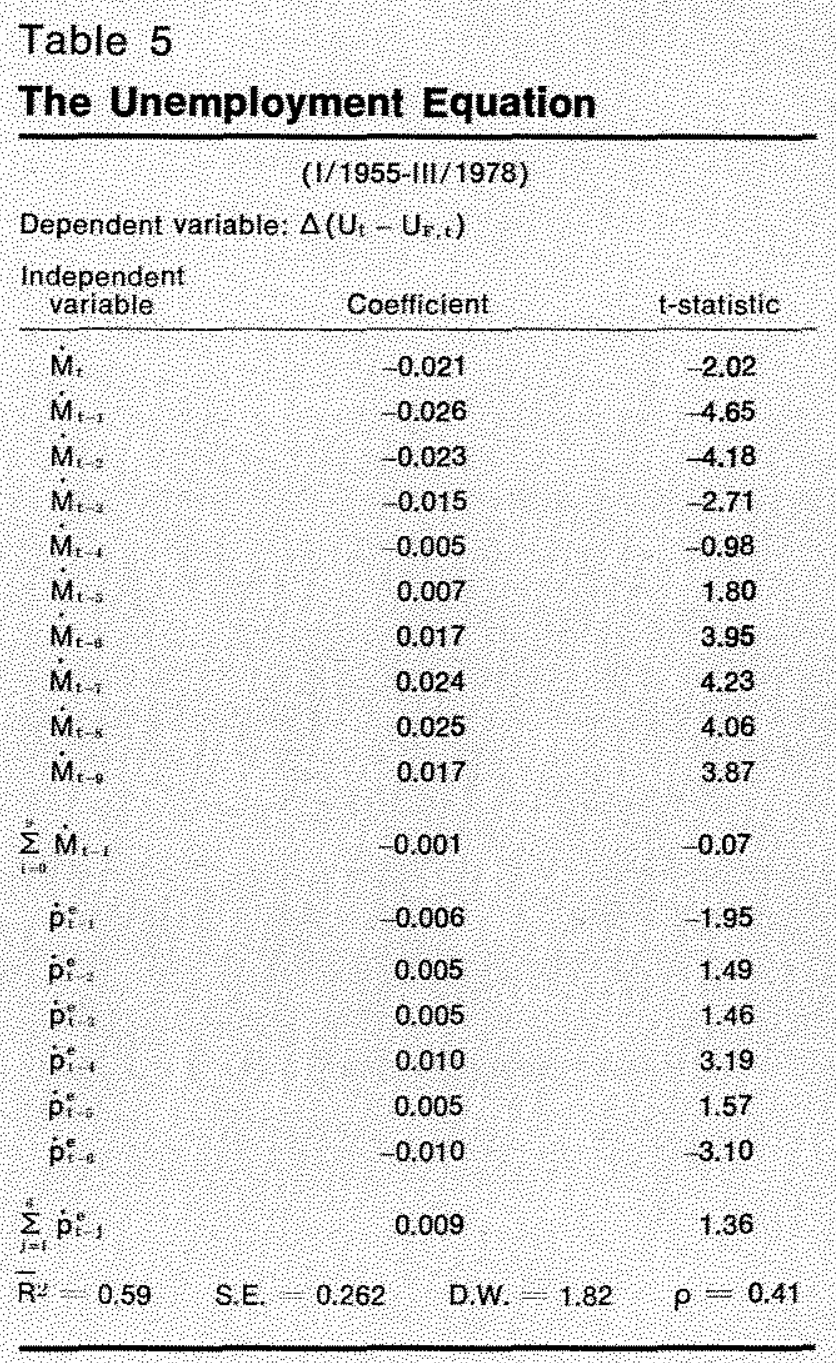

sequently, the excess unemployment rate is restored to its initial level. The energy price terms add significantly to the equation, while the sum effect is not significantly different from zero, as hypothesized above; the F-statistic for the addition of the lagged values of the change in the relative price of energy is $F_{6,66}=6.25$, which is significant at the 1 percent level. Finally, as hypothesized above, a once-and-forall rise in the relative price of energy initially reduces the unemployment rate. According to equation 9, the sum of the coefficients for period $t-1$ and $t-2$ is negative; thereafter, the cumulative sum is positive until period $t-6$, when the sum is positive but not significantly greater than zero.

Equation 9 was also estimated with the sum of the energy price coefficients set equal to zero. The $\mathrm{F}$ statistic for this constraint is $F_{1, s 6}=1.85$ which is not significant at the 5 percent level. Thus, the hypothesis 


\section{Chart 5 \\ Portion of the Change in the Unemployment Rate Due to Energy Price Changes (I/1970_III/1980)}

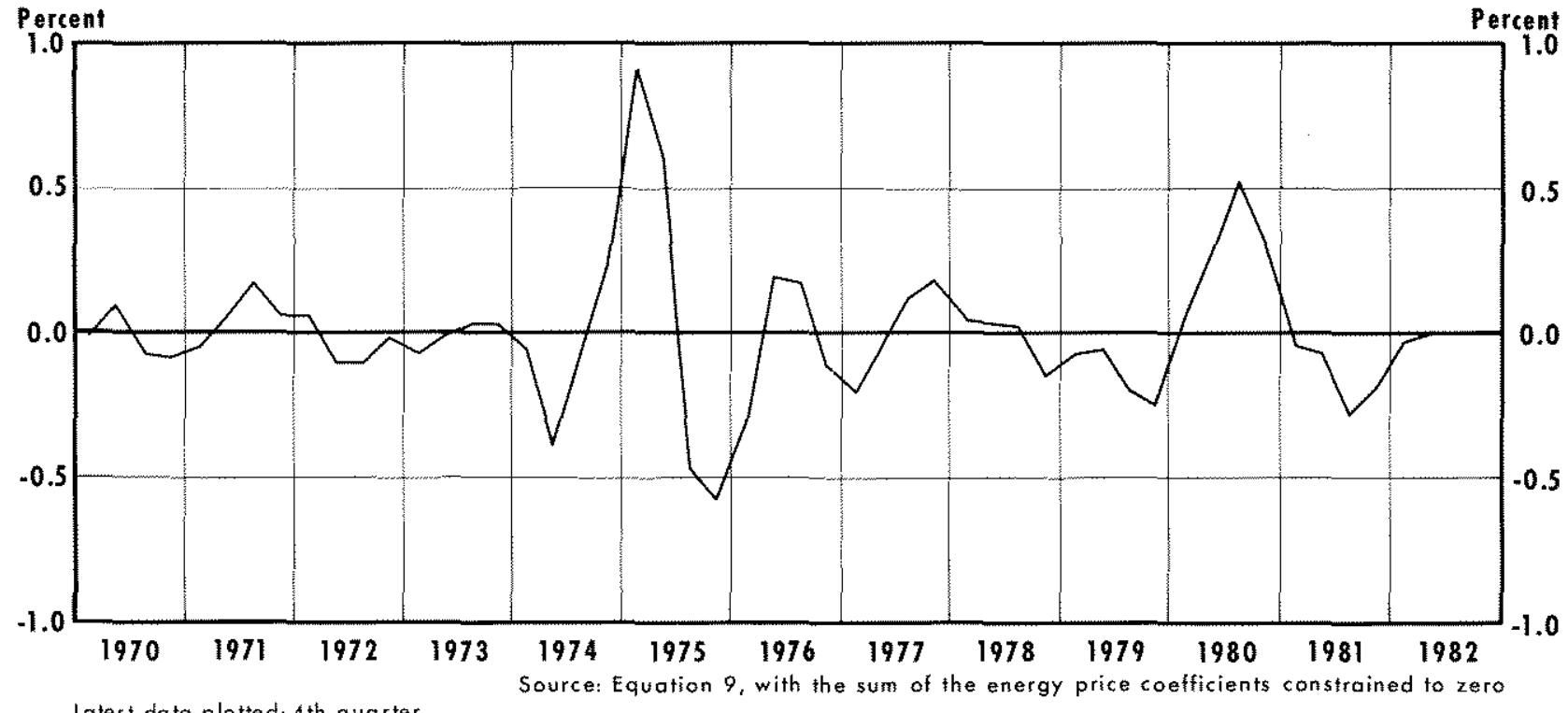

Latest doto ploted: 4 th ovarter

that the significant effects of a rise in the relative price of energy are temporary cannot be rejected. The individual coefficient estimates, with $t$-statistics, for the past six quarters are: $-0.008(-2.77), 0.004(1.13)$, $0.003(1.05), \quad 0.009(2.89), \quad 0.004(1.24)$ and -0.011 $(-3.81) .^{21}$

A post-sample simulation of equation 9 tracks changes in the excess unemployment rate from IV/ 1978 to III/1980 very well. The mean error for the eight quarters is -0.015 percentage points. The RMSE is 0.323 , which is large relative to the standard error of equation 9. However, in II/1980 and III/1980 there are relatively large errors reflecting unusually

\footnotetext{
21The estimates and tests for equation 9 were also conducted using an Amon polynomial to estinate the impact of energy price changes. A second degree polynomial with no endpoint constraints proved superior to higher order polynomials (third and fourth) for the energy price effect. The optimal lag is again six quarters for energy prices, and 10 quarters for money growth. The standard error of the equation is slightly lower, 0.261 . Only the significance of the energy price coefficients are noticeably changed by such an estimation procedure. These coefficients from $t-1$ to $t-6$, with t-statistics, are $-0.006(-2.40), 0.004(2.86), 0.009(5.82)$ $0.009(5.60), 0.003(2.12)$ and $-0.003(-3.28)$. The adjusted $\mathbf{R}^{2}$ for this equation is 0.59 . A local minimum standard errof occurs with 21 lagged values of money growth (S.E. $=$ 0.263 ) for lags up to 30 quarters.
}

slower, then faster, GNP growth and so an unusually larger, then smaller, rise in the unemployment rate. For the first six quarters of the simulation, the RMSE is only 0.177 percentage points, which is much smaller than the standard error of equation 9 . The mean error for the first six quarters is the same as for the eight quarters. This fit is also supported by extending the sample period for equation 9 through the third quarter of 1980 . The adjusted $R^{2}$ is 0.58 and the standard error is 0.267 . The sum statistics, and the pattern, magnitude and t-statistics for the individual coefficients are virtually the same as for the earlier period. The same results apply to the constrained version of equation 9 .

Chart 5 shows the impact of actual increases in energy prices on the change in the excess unemployment rate since the first quarter of 1970. The coefficients from the constrained version of equation 9 are used to compute these effects. Generally the effects are trivial, except in 1974-75 and in 1979-81. During the first three quarters of 1974 , the cumulative impact of the energy price increase was to reduce the unemployment rate by 0.5 percentage points. During the next three quarters, the excess unemployment rate rose 1.7 percentage points, and the difference was 
largely offset in the last two quarters of 1975. On average, the unemployment rate was 0.3 percentage points lower in 1974 and 0.7 percentage points higher in 1975 due to the $1973-74$ energy price increases. For the recent round of energy price increases, the estimates indicate that the unemployment rate was lowered by about 0.3 percentage points in 1979 , was unaffected on average in 1980 and will be 0.3 points higher in 1981 due to the economy's dynamic adjustment to higher energy prices.

Note that if the 1973-74 episode is dated from the first quarter of 1974 to the first quarter of 1976 , the positive cumulative impact of the sharp increase in energy prices occurs only in the four quarters of 1975 when it is $0.6,1.2,0.8$ and 0.2 percentage points, respectively. This period begins at the trough quarter of the recession. In the second instance, if the impact is summed beginning in the first quarter of 1979 , the cumulative impact is not positive until the third quarter of 1980, when it is 0.3 percentage points, and in the next three quarters, when it is about 0.5 percentage points. After mid-1981, the temporarily higher unemployment rate is quickly eliminated by the dynamic functioning of the product and labor markets.

In each instance, the temporary increase in the unemployment rate does not occur until the worst part of the output reduction is complete and the economy is apparently recovering on its own. Second, in each case, when the unemployment rate is temporarily high, the energy-price-induced component is a relatively small part of the total. Finally, in each case the highest levels of positive cumulative unemploy. ment impacts associated with energy price developments have been quickly reversed. Of course, these conclusions provide no support for exercising monetary restraint in the face of sharp energy price and price level surges. On the other hand, they do not warrant even temporary demand stimulus.

\section{SUMMARY AND CONCEUSION}

The sharp increase in energy prices in 1979 and 1980 reduced both potential output and productivity, and temporarily increased the inflation rate in the same way, and to the same extent, as in 1974-75. In addition, the absence of perfect price flexibility can give rise to a transition to short-run equilibrium during which total spending, actual output and the un employment rate are affected. These effects are strongly supported by the empirical estimates for the period ending in the third quarter of 1978 or in the third quarter of 1980 . The results support the claim that these effects are transitory.

The equation estimates indicate that a rise in the relative price of energy reduces potential output immediately but that the price level effect of this reduction occurs more slowly (over the subsequent year). Initially, total spending is dominated by reduced output with little change in prices; subsequently, prices are increased. There are strong positive output and GNP effects associated with these price increases toward the end of a six-quarter adjustment period. The output reduction due to an energy price increase initially is smaller than the decline in potential output, then overshoots it, before returning to the size of the permanent decline. The pattern of unemployment rate developments matches this outcome: Initially, the unemployment rate declines, then rises to higher levels before falling sufficiently so that, after six-quarters, an energy price increase has no effect on the unemployment rate.

The magnitude of the transitional effects on GNP prices, output and the unemployment rate have been estimated for the two sharp increases in the relative price of energy in 1973-74 and 1979-80. In 1973-74 and early 1975 there were relatively large reductions followed by relatively large increases in spending growth associated with a rise in the relative price of energy. On average, GNP growth was lowered 0.6 percentage points in $1973,1.5$ percentage points in 1974 and raised 1.5 percentage points in 1975 . Due to the 1979-80 episode, GNP growth is estimated to have been 0.8 percentage points lower in 1979 and 2.0 percentage points lower in 1980 . These effects are estimated to be offset by faster GNP growth in 1981. The extent of temporary inflation rate effects is estimated to be largest in 1974 and 1980 when energy price developments temporarily added 2.1 percentage points to measured inflation rates.

The temporary effects on real output growth are reflected in unemployment rate developments. The estimates show that energy price developments reduced the unemployment rate by 0.5 percentage points during the first three quarters of 1974 , then raised it over the next three quarters, so that at the peak of the unemployment rate in II/1975, 1.2 percentage points were associated with energy price increases. This transitional increase was eliminated quickly. In 1979-80, the peak positive impact of energy price increases is about 0.5 percentage points late in 1980 and early 1981; this impact is estimated to be eliminated by the end of 1981 . 
The empirical investigation is conducted so that the energy price effects are estimated using data from the period prior to the recent episode of price increases. Aside from providing a stronger test of the hypotheses using the 1979-80 increases, the approach provides an opportunity to examine the impact of the increased emphasis on money growth reductions announced in November 1978 and reinforced by the announcement of procedural changes in October 1979.
The simulations for GNP, inflation and unemployment conducted from IV/1978 to $111 / 1980$ indicate no change in the basic reduced-form relationships and no independent impact of these announcements or any actions intended to implement the slowing of money growth. Instead, the reduced-form relationships appear to explain spending, price, output and unemployment rate developments as well as they did previously.

\section{Appendix 1}

\section{The GNP Results Using an Almon Lag for Energy Price Changes}

The purpose of this appendix is to provide comparable estimates to equation 5 using an Almon polynomial distributed lag rather than an ordinary distributed lag. When equation 5 is estimated for the period I/1955-III/1978 using both third and fourth degree polynomials, with and without end-point constraints, for up to 16 lagged terms for the growth in the relative price of energy, the "best" equation is found using the third degree polynomial with six lagged terms without end-point constraints. The specification for the other variables is the same as in equation 5 in the text. The estimated equation for the period I/1955-III/1978 is:

(1.1) $\mathrm{GNP}_{\mathrm{t}}=\frac{2.681}{(3.25)}+\frac{1.124}{(7.59)} \sum_{i=0}^{4} \mathrm{w}_{t-1}^{0} \dot{\mathrm{M}}_{\mathrm{t-1}} \underset{(-0.04)}{0.003} \sum_{j=0}^{4} \mathrm{w}_{t-1}^{1} \dot{\mathrm{E}}_{\mathrm{t}-1}$

$$
\begin{gathered}
\frac{-0.475 S_{i}+0.024 \sum_{k=8}^{8} w_{t-k}^{*} \dot{p}_{i-k}^{e}}{(-3.83)} \\
\bar{H} 2=0.53 \quad \text { S.E. }=2.93 \quad \text { D.W. }=1.96
\end{gathered}
$$

where the actual coefficients on $\dot{p}^{z-k}$ are:

$\begin{array}{llll}\text { current } & -0.028(-0.96) & & \\ t \cdots-1 & -0.010(-0.65) & t-4 & -0.041(-2.34) \\ t-2 & -0.001(-0.07) & t-5 & -0.004(-0.22) \\ t-3 & -0.029(-2.18) & t-6 & 0.116(4.01)\end{array}$

This estimate is similar to equation 5 in the text. The sum of the money growth coefficients is not significantly different from one, and the sums of the expenditure growth variables and energy price change variables are each not significantly different from zero. The pattern of energy price effects and magnitude are the same as in equation 5. The fit of the equation is essentially the sarne as for equation 5 . An $F$-test of the three additional coefficients estimated in equation 5 indicates they do not add significantly to the explanatory power of equation 1.1. The F-statistic for the addition of the energy price variables to equation 4 in the text is $F_{4,8 s} \ldots 4.43$, which is signifcant at the 1 percent level. When equation 1.1 is used to simulate GNP in the eight quarter post-sample period, the results are essentially the same as the results in table 1 in the text,

When equation 1.1 is estimated over the sample period ending in III $/ 1980$, the optimal lag length and polynomial degree remain the same, as do the other properties described above. The Fustatistic for the addition of the energy price variables is $\vec{F}_{4,91}=5.14$, which is significant at the 1 percent level. The coefficients on the changes in the relative price of energy (from current to $t-6$ ) with $t-s t a-$ tistics are: $-0.041(-1.56), 0.008(0.56), 0.003(0.17)$, $-0.023(-1.96),-0.036(-2.14), 0.003(0.15)$ and 0.118 (4.17). The sum of the energy price coefficients is 0.024 (0.44). The adjusted $R^{2}$ of the equation is 0.54 and the standard error is 2.93 percent. The Durbin-Watson statistic is 2.00 .

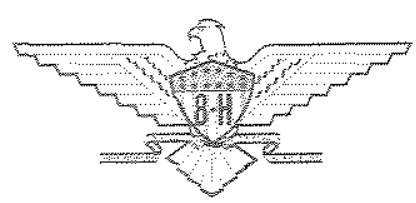

